\title{
Urban Land-use and Traffic Congestion: Mapping the Interaction
}

\author{
${ }^{1 *}$ Ph.D. Candidate James Kanyepe (D), 2 Prof. Dr. Marian Tukuta (D), 3 Prof. Dr. Innocent Chirisa
}

\begin{abstract}
1 and 2 Department of Supply Chain Management, Chinhoyi University of Technology, Zimbabwe
3 Department of Demography Settlement \& Development, University of Zimbabwe, Zimbabwe E-mail 1: jameskanyepe@gmail.com, E-mail 2: paidamoyo2016@gmail.com

E-mail 3: innocent.chirisa@gmail.com
\end{abstract}

\begin{tabular}{|l|}
\hline ARTICLE INFO: \\
\hline Article History: \\
Received 25 October 2020 \\
Accepted 15 December 2020 \\
Available online 19 December \\
2020 \\
\hline Keywords: \\
Land-Use; \\
Peak Hour; \\
Traffic Congestion; \\
Transport; \\
Travel Patterns; \\
Travel Behavior. \\
\end{tabular}

This article is an open access
article distributed under the terms and
conditions of the Creative Commons
Attribution (CC BY) license
This article is published with open
access at www.ijcua.com

\section{ABSTRACT}

The interaction between transport, land-uses and travel patterns produce diverse transportation problems in urban cities with traffic congestion as the most visible manifestation. Traffic congestion is a frequent phenomenon in most cities around the globe. This paper reviews the interaction between landuse traffic congestion through published literature. The objective of this study is to encourage and provide researchers with future research directions in land-use and traffic congestion. For this purpose, a systematic review was performed analysing 45 articles from the year 2010 to 2020 using a descriptive approach. Subsequently, the results of the study show that although the interaction between land-use and traffic congestion has gained currency in developed countries far less is known on this subject in developing parts of the world, though new evidence is steadily accumulating. Consequently, limitations of this work are presented, opportunities are identified for future lines of research. Finally, the conclusion confirms the need for further research addressing the methodological concerns.

JOURNAL OF CONTEMPORARY URBAN AFFAIRS (2021), 5(1), 77-84. https://doi.org/10.25034/ijcua.2021.v5n1-6

Copyright @ 2021 James Kanyepe, Marian Tukuta, Innocent Chirisa.

\section{Introduction}

This systematic review aims to examine the recent literature on the interaction between land-use and traffic congestion. Traffic congestion has become a ubiquitous problem worthy of policy attention and citizens alike (Shahgholian \& Gharavian, 2018; Uniyal \& Gandhi, 2019). The rush hour has become a two or three-hour peak period, and congestion recurs mornings, midday, midevening, and on weekends as well (Jayasooriya \& Bandara,
2017). Mir Shabbar, Muhammad, and Syed Fazal Abbas (2014) argue that unplanned landuse results in traffic congestion. Other scholars have asserted a connection between land use and traffic congestion in urban areas (Colonna, Berloco, \& Circella, 2012; Kuzmyak, 2012;

*Corresponding Author:

Department of Supply Chain Management, Chinhoyi University of Technology

Email address: jameskanyepe@gmail.com 
Mukherjee, et al., 2014; Zhang, et al., 2017). However, the magnitude and significance of a relationship between land use and congestion remain unclear. Two major impediments to statistically sound, comparative studies of land use and congestion exist a lack of good measures of congestion; and the difficulty in modelling the complex interrelationships between congestion, land use, and transport infrastructure (Wang, 2010).

Traffic congestion is a comparison of the use of transportation systems with the capacity of the transportation system. In a way, land-use affects traffic congestion in both dimensions. On the supply side, the street network determines the number of lane-miles in a given area whereas, on the demand side, different types of land-uses will cause variation in travel behaviour (such as travel frequency, length and mode choice) which in turn influences the level of congestion (Ewing \& Cervero, 2017). A sizeable number of studies have investigated the impact of density development (compact or sprawl) on vehiclemiles traveled (VMT), traffic volume (e.g. annual total traffic volume, and volume to capacity ratio), throughput (e.g. vehicles per hour, and average daily traffic per lane), travel time and speed, travel delay, and congestion indices (e.g. travel time index and roadway congestion index) (Cervero, 2013; Engelfriet, 2015; Ewing, et al., 2014; Ewing, et al., 2018). However, these studies have reported mixed links between density and traffic congestion measures.

In response to the new urbanism and compact city concepts, developments with diverse uses are strongly thought to maintain sustainability and reduce car dependency (Kusumastuti \& Nicholson, 2017). There is relatively strong and significant empirical evidence that diversity reduces the individual VMT (Cervero, 2013; Geyer \& Quin, 2019; Spears, Houston, \& Boarnet, 2013). A balance between jobs and housing might reduce the length of commute trips thus reducing traffic congestion and air pollution. Scholars have been arguing that the reasons for the continued lengthening of commuting times and the marked deterioration of traffic conditions are the results of the increasing job and housing imbalance in many metropolitan areas (Niedzielski, O'Kelly, \& Boschmann, 2015; Zhang et al., 2017). A community is considered balanced when residential and employment distributions are approximately equal (Jiangping, Chun, Xiaojian, Wei, \& Peng, 2014; Masoumi et al., 2018; J. Zhou \& Long, 2014).
Areas with diverse uses are found to significantly increase slow modes shares, increase walk mode choice for work trips (Ton, et al., 2019) and non-work trips (W. Zhou \& Li, 2016). The proximity of commercial centers to the residence location has a strong impact on increasing the walk mode share for non-work trips (Alqhatani, Setunge, \& Mirodpour, 2014). Regarding public transport (transit), similarly, empirical evidence is found in the literature about the positive impact of the land-use mixture in promoting the frequency and mode share of public transport. Numerous scholarly efforts have observed that walking distance and walking time are critical factors in determining mode choice (for example whether to use public transport or not) (Durand et al., 2016; Ewing \& Cervero, 2010; Grisé, Wasfi, Ross, \& El-Geneidy, 2019). A plethora of studies has investigated whether urban design increase or reduce traffic congestion (Ewing \& Cervero, 2010). Household VMT could be significantly reduced with an increase in bicycle lane density or with an increase in intersection density (Litman, 2012). In contrast, residential areas with a high proportion of intersections are empirically found to provide pedestrian-friendly land-uses. These areas significantly increase the active transport trip frequency and increase the probability of the walk mode choice for work and other trips alike

Another body of research investigated the impact of destination accessibility on traffic congestion (Ewing \& Cervero, 2010; Hasibuan, et al., 2014; Suzuki, et al., 2013). A development toward a more sustainable transport system (as in increasing walking, cycling and public transport, and decreasing car-use) has been regarded as an important aim in the field of transportation research in the last decades due to an array of reasons, including environmental issues and congestion. Therefore, the objective of this literature review is to present current issues surrounding the interaction between land-use and traffic congestion. For this purpose, a systematic literature review published from 2010 to 2020 is carried out. A systematic literature review was chosen due to its transparent and replicable characteristics, and its identification of research gaps and occurrence for further investigation. This review analyses the literature from a descriptive standpoint, to assess advancement and emphasize the areas of further research required. Thus, this study aims to answer the question: what sort of a relationship 
exists between land-use and traffic congestion? For this purpose, the present review is organized as follows: Section 2 presents the methodology followed by Section 3 which presents the results of the investigation. Section 4 presents the discussion of the topic, section 5 presents the research gap, section 6 presents limitations and future research and finally, Section 7 presents a brief conclusion.

\section{Methodology}

To provide a vigorous review of the literature we performed a systematic review on the relationship between land-use and traffic congestion. The inclusion criteria were (i) publications indexed in Elsevier, ScienceDirect and JSTOR databases, (ii) publication date between 2010 and 2020 (iii) written in English, and (iv) particular search terms covered. Editorial material, books, or book chapters, technical reviews were excluded from our research. We employed the Systematic Review Data Repository (SRDR), a cutting-edge tool for extraction, administration and inspection of data for our systematic review. Gathering and analysing publicly accessible literature we required no institutional ethics approval before initiating our research. During the period August 2019 we conducted a quantitative literature review of Elsevier, ScienceDirect, and JSTOR databases, with search terms including "landuse" and "traffic congestion" Out of 436 papers found, dated from 2010 to 2020 , only 45 articles met the eligibility criteria. These articles were analysed and classified according to different categories based on their characteristics. Descriptive analysis was adopted and it included the geographical framework and research methodologies being used. Fig 1 depicts the sequence of steps undertaken for this research methodology.

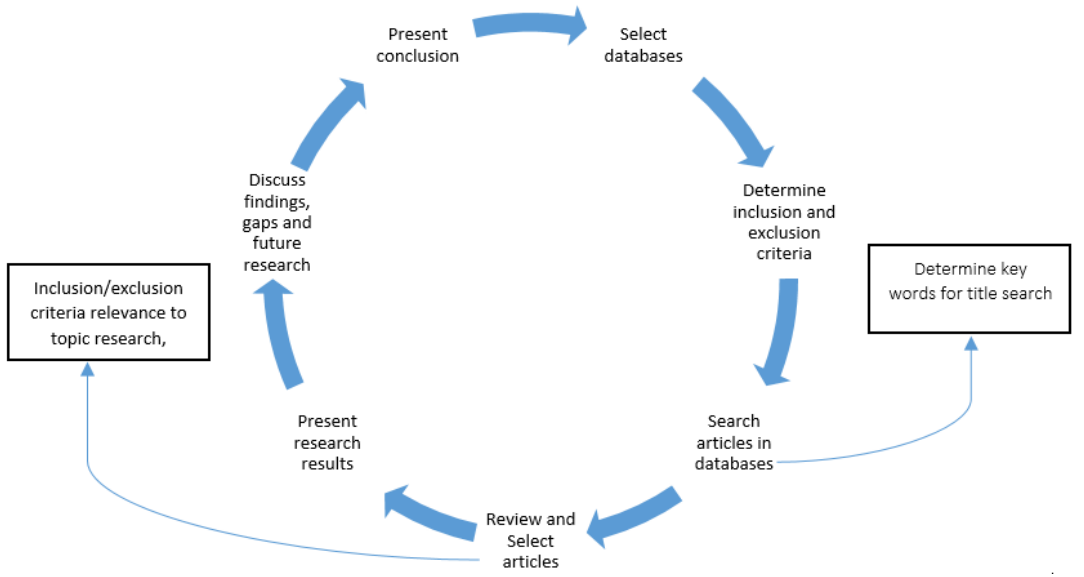

Figure 1. The sequence of steps taken for this research methodology.

\section{Results}

The results comprise of descriptive analysis of the 45 articles. The descriptive analysis consists in identifying and classifying the articles by geographical framework and analysis of research methodology.

\subsection{Analysis of articles by the geographical framework}

Table 1 shows the geographical framework of articles used to analyse the interaction of landuse and traffic congestion.

Table 1. Distribution of articles by the geographical framework.

Geographical Framework

\begin{tabular}{c|c} 
Africa & 1 \\
America & 20 \\
Asia & 11 \\
Australia & 4 \\
Europe & 9
\end{tabular}

The geographical distribution shows that the American continent dominates research on land-use and traffic congestion. For instance, Wang (2010) used a multi-dimensional approach to measure the impact of land-use and traffic congestion in Florida. Kuzmyak (2012) performed a detailed analysis of the relationships between higher-density land-use and traffic conditions in four Phoenix transportation corridors in the United States. Using aggregated commute data from the American Community Survey, Gordon and Lee found that job dispersion, rather than just density or population dispersion is the critical factor for congestion and travel time. Ewing, Keith, et al. (2018) conducted a study in the United States and found that compact, mixed-use development is inherently more efficient and sustainable, using less land and reducing 
private vehicle use rates by bringing people and activities closer together, and also providing densities that are capable of supporting walking and effective transit services. Adetunji (2020) stated that as population increase, the number of automobiles, tricycles, and motorcycle also increase.

Some notable studies conducted in Asia include a study conducted by Patel, Kheni, Patel, Patel, and Chauhan (2019) who evaluated traffic congestion using a comparative land-use pattern in Surat, India, and found that land-use impacts the movement of traffic. Zhang et al. (2017) proposed a new method to describe, compare, and classify the traffic congestion points in Beijing, China, using the online map data and further revealed the relationship between traffic congestion and land-use. Shubho and Neema observed that careless unplanned development of land-uses in Dhaka, Bangladesh has resulted in perpetual traffic congestion along with pollution, thereby aggravating its sustainability. Mukherjee et al. (2014) carried a study to determine the effects of heterogeneity in land-use distribution on traffic congestion in rapidly urbanising Ranchi City, capital of Jharkhand state, India and found that there is a positive relationship between heterogeneity in land-use distribution and traffic congestion. There is a paucity of studies on the research topic in the African continent. The only study obtained from the search was a study by Oduwaye, Alade, and Adekunle (2011) who surveyed the land-use and pattern along the Lagos-Badagry corridor, in the Lagos metropolis, Nigeria.

\subsection{Analysis of Research Methodologies}

This sub-section presents a comprehensive analysis of the methodologies that were used to uncover the relationship between land-use and traffic congestion. Although a consensus has been reached on the interaction of land-use and traffic congestion, the magnitude and significance of a relationship between the two are still unclear suggesting that there might be inconsistencies in the methods used to analyse this topic. The differences in conceptual models in previous studies are likely to generate contradictory results. For instance, land-use is measured in different ways (Newman \& Kenworthy, 2015) and so is congestion (Rao \& Rao, 2012). Ewing, et al., (2018) assert that no one has yet determined, using credible landuse metrics and credible congestion data, the net effect of those countervailing forces on area-wide congestion. Cutsinger et al., (2010) points that there are eight dimensions of the metropolitan structure, namely: density, continuity, concentration, clustering, centrality, nuclearity, mixed uses, and proximity.

Ewing et al. (2014) used the compactness/sprawl index metrics methodology to measure sprawl in 162 U.S urbanised areas. Following the same logic, Sarzynski, Galster, and Stack (2014) explored the multi-dimensional variations and changes in U.S. metropolitan land-use patterns during the 1990s. Jaeger and Schwick (2014) have conducted analyses extending the time considerably. They developed a Weighted Urban Proliferation (WUP) metric to assess urban sprawl in Switzerland and present for the first time quantitative figures about the development of sprawl for an entire country over a time of more than a century. Their method is suitable for studying changes in regional sprawl patterns over time and offers valuable tools for analysing the changing nature of sprawl and urban development historically. European Environmental Agency used urban permeation (UP) and WUP as sprawl metrics for all European countries. Fuladlu (2019) that urban sprawl does not promote autodependency.

Cutsinger et al., (2010) used a multidimensional conceptualization of land-use to prove to be an important improvement. Cervero (2013) conducted a cross-sectional study design with Structural Equation Modelling (SEM). Using compactness/sprawl metrics they found that an increase in compactness reduces the amount of driving people to do, but also concentrates the driving in smaller areas. Using data from 45 county-level urban areas of 2007 in the State of Florida, Wang (2010) measured 12 indices of land-use and 3 measures of traffic congestion, grouping them into 5 distinct factors and conducting bivariate analysis between variables. Kuzmyak (2012) used the volume to capacity ratio (V/C ratio) to measure congestion and density, diversity, and destinations to measure land-use.

In light of the articles reviewed, it clear that there is a lack of consensus on the credible variables, congestion data used, population size, and consideration for reverse causation and time-lags. This lack of consensus suggests 
that further refinement of the models may be necessary, paying special attention to these methodological issues.

\section{Discussions}

This study conducts a literature review of articles on land-use and traffic congestion, published from 2010 to 2020, in Elsevier, ScienceDirect, and JSTOR databases. This research investigates the available literature under several constraints: Time period, English language, three database sources, research and literature articles only with different variants on search keywords, and land-use and traffic congestion emphasis. Furthermore, this research classifies the extracted articles under different approaches: Distribution of articles by the geographical framework and research methodology, and tools and techniques used for analysis. The results of these classifications have facilitated the discussion on the current status and progress on traffic congestion and land-use. Therefore, the key findings will be discussed, followed by the research gaps and future research opportunities.

Policymakers, including transport planners and transport engineers, have become increasingly aware and interested in understanding the interaction between land-use and traffic congestion. However, there is a paucity of research on the research topic in developing countries. Out of 45 articles used for this study, the American continent had $44 \%$, followed by Asia (26\%), Europe (21\%), and Australia (8\%) whereas African had less than $1 \%$ of the articles. The study also revealed that the United States has been the major contributor to land-use and traffic congestion articles, followed by China, Bangladesh, Europe, and Nigeria. The study revealed that linear regression is the most used technique (21 articles) followed by correlation analysis (17 articles) and the least used approach is Structural Equation Modelling (SEM) (7 articles), Ewing, Tian, and Lyons (2017) used a cross-sectional study, regression analysis along with Structural Equation Modelling. Kuzmyak (2012) developed a set of regression models to quantify the effects of key land-use variables on household vehicle ownership and VMT, illustrating the mitigating effects of higher density, better mix, and better transit accessibility.

Density is the most commonly used measure of land-use. From the articles used, $87 \%$ used density, design, and diversity concerning traffic congestion. Wang (2010) adapted the multidimensional approach to measure land-use and traffic congestion. He obtained data obtained from 45 county-level urban areas as of 2007 in the State of Florida. In the conceptual model, he developed three (3) congestion indicators - Roadway Capacity Index (RCI), Travel Time Index, and delay per capita, which were correlated with twelve (12) land-use measures, grouping urban form indices into 5 distinct factors, and conducting bivariate analyses between variables. Zhang et al. (2017) used linear regression analysis to determine the influence of the high proportion of commercial land-use on traffic congestion. The findings show that there are studies on land-use and traffic congestion in developing countries particularly in Africa are scarce. Furthermore, the study findings show that there are inconsistencies in the methods that were used to analyze the topic.

\section{The Research Gaps}

The current body of knowledge lacks empirical insights into the interaction between land-use and traffic congestion in developing countries. There has been inadequate attention to and discussion on how land-use influences traffic congestion in developing countries. However, a great amount of literature-based evidence on the research topic is abundant in developed countries but findings from these studies have been refuted based on methodological concerns. For instance, a sizeable number of scholars have focused on how density influences traffic congestion but the influence of other measures of land-use (such as diversity, design, destination accessibility, and distance to transit) on traffic congestion is scarce. Besides, previous studies have used basic measures of traffic congestion and obtained varying results. For example, Kuzmyak (2012) used volume capacity (V/C ratio) and found that that there was considerably less congestion despite densities that were many times higher in four Phoenix transportation corridors in the United States of America while Zhang et al. (2017) used commute time and found that a reasonable ratio of land-use could efficiently reduce traffic congestion. However, studies exploring the interaction between land-use and traffic congestion using a multi-dimensional approach are limited. Therefore, it is important to address the deficiencies exhibited by basic 
measures through the use of a multidimensional approach.

\section{Limitations and Future Research}

This sections present limitations and further research opportunities. The restriction of database access availability has limited the research and thus articles from other sources of primary importance on the interaction between land-use and traffic congestion could have been excluded from processing. The keywords used may not be all-inclusive. The review was carried out on 45 articles; therefore, the exploration of more articles could broaden the conceptualization and knowledge of empirical research, and issues currently addressed regarding land-use and traffic congestion. The land-use dimensions that influence traffic congestion have not been studied in the same magnitude particularly in developing countries. Besides, a plethora of research has not yet agreed on the proper methodology to use when examining the interaction between the two. Likewise, the current body of literature on the research topic can be criticised for a lack of insight into the aspects that make a good congestion measure. For example, commute time computes travel time across different travel modes; ADT/lane and commute time are averaged numbers across time and space while delay per capita is limited to peak hours and only for arterial and freeways. Therefore, research on the interaction between land-use and traffic congestion must evolve from these basic indicators and use multi-dimensional measures. Moreover, by increasing the number of articles, more specific topics can be analysed and trends can be identified with greater precision. Furthermore, there is a need to segregate empirical research for developed and developing countries due to intrinsic differences that may result in distinctive findings.

\section{Conclusions}

Research on the interaction between land-use and traffic congestion in developing economies has begun and advanced in the last two decades, however it is still in its infancy when compared to research in developed countries. This study attempted to enrich the knowledge of the research field by carrying out a literature review of articles available on specific databases in the last decade. The undertaken different approaches classification and analysis of the selected papers helped to provide and discuss outcomes on current research status. Although a consensus has been reached on the interaction of land-use and traffic congestion, the magnitude and significance of a relationship between the two are still unclear thus a critical knowledge gap that needs to be filled. The ongoing debate with regards to the significance of the relationship is intensified by inconsistencies in methodological approaches, lack of multi-dimensional measures for both land-use and traffic congestion. Further research can be directed toward addressing these issues. It is also recommended to conduct a study on the topic in developing countries as far less is known on this subject.

\section{Acknowledgement}

This research did not receive any specific grant from funding agencies in the public, commercial, or not-for-profit sectors.

\section{Conflict of interests}

The authors declare no conflict of interest.

\section{References}

Adetunji, M. A. (2020). Automobile Trips to School and Safety Perspectives of Unplanned Lokoja Metropolis in North Central Nigeria. Journal of Contemporary Urban Affairs, 4(1), 61-70. https://doi.org/10.25034/ijcua.2020.v4n1-6

Alqhatani, M., Setunge, S., \& Mirodpour, S. (2014). Can a polycentric structure affect travel behaviour? A comparison of Melbourne, Australia and Riyadh, Saudi Arabia. Journal of Modern Transportation, 22(3), 156-166. https://doi.org/10.1007/s40534014-0054-y

Cervero, R. B. (2013). Linking urban transport and land use in developing countries. Journal of Transport $\begin{array}{lll}\text { and Land Use, 6(1), 7-24. } & \end{array}$ https://doi.org/10.5198/jtlu.v6i1.425

Colonna, P., Berloco, N., \& Circella, G. (2012). The Interaction between Land Use and Transport Planning: A Methodological Issue. Procedia Social and Behavioral Sciences, 53, 84-95. https://doi.org/10.1016/j.sbspro.2012.09.862

Durand, C. P., Oluyomi, A. O., Gabriel, K. P., Salvo, D., Sener, I. N., Hoelscher, D. M., \& Kohl, H. W. (2016). The Effect of Light Rail Transit on Physical Activity: Design and Methods of the Travel-Related Activity in Neighborhoods Study. Frontiers in Public Health, 4, 103. https://doi.org/10.3389/fpubh.2016.00103 
Engelfriet, L. (2015). The impact of urban density on car dependency and related energy consumption. Vrije Universiteit, Amsterdam, Netherlands. Retrieved from https://spinlab.vu.nl/wpcontent/uploads/2016/09/Research_Project_Lara_E ngelfriet.pdf

Ewing, R., \& Cervero, R. (2010). Travel and the Built Environment. Journal of the American Planning Association, $\quad 76(3)$, 265-294. https://doi.org/10.1080/01944361003766766

Ewing, R., \& Cervero, R. (2017). "Does Compact Development Make People Drive Less?" The Answer Is Yes. Journal of the American Planning Association, $\quad 83(1)$, 19-25. https://doi.org/10.1080/01944363.2016.1245112

Ewing, R., Hamidi, S., \& Grace, J. B. (2014). Urban sprawl as a risk factor in motor vehicle crashes. Urban Studies, 53(2), 247-266. https://doi.org/10.1177/0042098014562331

Ewing, R., Keith, B., \& Alexander, B. (2018). Best Practices in Metropolitan Transportation Planning: New Advances, Approaches, and Best Practices. London:

Routledge.https://doi.org/10.4324/9781351211345.

Ewing, R., Tian, G., \& Lyons, T. (2018). Does compact development increase or reduce traffic congestion? Cities, 72, 94-101. https://doi.org/10.1016/j.cities.2017.08.010 Retrieved from http://www.sciencedirect.com/science/article/pii/S0 264275116304498

Fuladlu, K. (2019). Urban Sprawl Negative Impact: Enkomi Return Phase. Journal of Contemporary Urban Affairs, 3(1), 44-51. https://doi.org/10.25034/ijcua.2018.4709

Cutsinger, J., Galster, G., Hanson, R. and Towns, D. (2010). Verifying Sprawl's Distinct Dimensions. Journal of Urban Affairs, 27(3), 235-259. https://doi.org/10.1111/j.0735-2166.2005.00235.x

Geyer, H., \& Quin, L. (2019). Social diversity and modal choice strategies in mixed land-use development in South Africa. South African Geographical Journal, 101(1), $1-21$. https://doi.org/10.1080/03736245.2018.1522270

Grisé, E., Wasfi, R., Ross, N. A., \& El-Geneidy, A. (2019). Evaluating methods for measuring daily walking to public transport: Balancing accuracy and data availability. Journal of Transport \& Health, 15, 100638. https://doi.org/10.1016/j.jth.2019.100638
Hasibuan, H. S., Moersidik, S., Koestoer, R., \& Soemardi, T. P. (2014). Using GIS to integrate the analysis of land-use, transportation, and the environment for managing urban growth based on transit oriented development in the metropolitan of Jabodetabek, Indonesia. IOP Conference Series: Earth and Environmental Science, 18, 012177. https://doi.org/10.1088/1755-1315/18/1/012177

Jayasooriya, S. A. C. S., \& Bandara, Y. M. M. S. (2017, 29-31 May 2017). Measuring the Economic costs of traffic congestion. Paper presented at the 2017 Moratuwa Engineering Research Conference (MERCon).

https://doi.org/10.1109/MERCon.2017.7980471

Jiangping, Z., Chun, Z., Xiaojian, C., Wei, H., \& Peng, Y. (2014). Has the legacy of Danwei persisted in transformations? the jobs-housing balance and commuting efficiency in Xi'an. Journal of Transport Geography, 40, 64-76. https://doi.org/10.1016/j.jtrangeo.2014.04.008

Kusumastuti, D., \& Nicholson, A. (2017). Mixed-Use Urban Planning and Development. Building Research Association New Zealand, New Zealand. Retrieved from http://hdl.handle.net/10092/15417

Kuzmyak, J. R. (2012) Land Use and Traffic Congestion A. D. o. T. R. Center. Retrieved from https://apps.azdot.gov/files/ADOTLibrary/publicati ons/project_reports/pdf/az618.pdf

Litman, T. (2012). Evaluating accessibility for transportation planning. Victoria Transport Policy Institute, Victoria, Canada. Retrieved from https://azdhs.gov/documents/prevention/nutritionphysical-activity/nutrition-physical-activityobesity/healthy-communities/accessibilitytransportation-planning.pdf

Masoumi, H., Gouda, A. A., Layritz, L., Stendera, P., Matta, C., Tabbakh, H., \& Fruth, E. (2018). Urban Travel Behavior in Large Cities of MENA Region: Survey Results of Cairo, Istanbul, and Tehran. In: Center for Technology and Society.

Mir Shabbar, A., Muhammad, A. S. M., Noman, \& Syed Fazal Abbas, B. (2014). Estimation of Traffic Congestion Cost-A Case Study of a Major Arterial in Karachi. Procedia Engineering, 77, 37-44. https://doi.org/10.1016/j.proeng.2014.07.030

Mukherjee, A. B., Pate, N., \& Krishna, A. P. (2014). Development of heterogeneity index for assessment of relationship between land use pattern and traffic congestion. International Journal for Traffic \& Transport Engineering, 4(4), 397-414. https://doi.org/10.7708/ijtte.2014.4(4).04 
Niedzielski, M. A., O'Kelly, M. E., \& Boschmann, E. E. (2015). Synthesizing spatial interaction data for social science research: Validation and an investigation of spatial mismatch in Wichita, Kansas. Computers, Environment and Urban Systems, $\quad 54, \quad 204-218$. https://doi.org/10.1016/j.compenvurbsys.2015.09.0 04

Newman, P. and Kenworthy, J. (2015). The End of Automobile Dependence: How Cities Are Moving Beyond Car-Based Planning. Island Press: USA. https://doi.org/10.5822/978-1-61091-613-4

Oduwaye, L., Alade, W., \& Adekunle, S. (2011). Land use and traffic pattern along Lagos-badagry corridor, Lagos, Nigeria: na. Retrieved from https://conference.corp.at/archive/CORP2011_233. pdf

Patel, S., Kheni, A., Patel, H., Patel, M., \& Chauhan, D. (2019). Evaluation Of Traffic Congestion Using Comparative Land Use Pattern-A Case Study Of Surat City. International Research Journal of Engineering and Technology, 6(04), 1282-1284.

Rao, A. M. and Rao, K. R. (2012). Measuring Urban Traffic Congestion - A review, Inter. Journal for Traffic and Transportation Engineering, 2(4), 286305. http://dx.doi.org/10.7708/ijtte.2012.2(4).01

Shahgholian, M., \& Gharavian, D. (2018). Advanced traffic management systems: an overview and a development strategy. arXiv preprint arXiv:1810.02530.

Spears, S., Houston, D., \& Boarnet, M. G. (2013). Illuminating the unseen in transit use: A framework for examining the effect of attitudes and perceptions on travel behavior. Transportation Research Part A: Policy and Practice, 58, 40-53. https://doi.org/10.1016/j.tra.2013.10.011

Suzuki, H., Cervero, R., \& Iuchi, K. (2013). Transforming Cities with Transit: The World Bank.https://doi.org/10.1596/978-0-8213-9745-9.

Ton, D., Duives, D. C., Cats, O., Hoogendoorn-Lanser, S., \& Hoogendoorn, S. P. (2019). Cycling or walking? Determinants of mode choice in the Netherlands. Transportation Research Part A: Policy and Practice, 123, 7-23. https://doi.org/10.1016/j.tra.2018.08.023

Uniyal, H., \& Gandhi, H. (2019). Traffic CongestionCauses and Solution: A Study of Kota City. International Journal of Trend in Scientific Research and Development, 2(2).
Wang, R. (2010). Measuring Urban Form and Examining Its Impact on Traffic Congestion in Florida. University of Florida, Florida. Retrieved from http://ufdc.ufl.edu/UFE0042633/00001

Zhang, T., Sun, L., Yao, L., \& Rong, J. (2017). Impact Analysis of Land Use on Traffic Congestion Using Real-Time Traffic and POI. Journal of Advanced Transportation, $\quad 2017, \quad 7164790$. https://doi.org/10.1155/2017/7164790

Zhou, J., \& Long, Y. (2014). Jobs-Housing Balance of Bus Commuters in Beijing: Exploration with LargeScale Synthesized Smart Card Data. Transportation Research Record, 2418(1), 1-10. https://doi.org/10.3141/2418-01

Zhou, W., \& Li, Z. (2016). Determining Sustainable Land Use by Modal Split Shift Strategy for Low Emissions: Evidence from Medium-Sized Cities of China. Mathematical Problems in Engineering, 2016 , 2745092 https://doi.org/10.1155/2016/2745092

Check for

Updates

How to cite this article:

Kanyepe, J., Tukuta, M \& Chirisa, I. (2021). Urban Land-use and Traffic Congestion: Mapping the Interaction. Journal of Contemporary Urban Affairs, 5(1), 77-84. https://doi.org/10.25034/ijcua.2021.v5n2-6 